\title{
Introduction: the Nordic welfare state as a state of civilisation
}

\section{Sakari Hänninen, Kirsi-Marja Lehtelä and Paula Saikkonen}

The aim of this book is to contribute to a more profound understanding of the functioning of the Nordic welfare states from a relational perspective. This perspective opens up an opportunity to understand these societies as states of civilisation. Even if there is a noteworthy connection to the present ongoing discussion on the relational welfare state and relational welfare in Great Britain (Cooke and Muir, 2012), the relational character of the Nordic welfare states has a much longer and more conclusive history. The challenges of the Nordic welfare states cannot be approached only as technical or instrumental issues, but must be seen as questioning the deep social, cultural and political foundations of these societies. The answers to these challenges must be articulated in a similar fashion.

The nature and functioning of the Nordic welfare states have been a popular research topic in several disciplines, which have also formulated their research agendas and questions, made their analyses and articulated their answers along disciplinary lines. In this fashion our piecemeal understanding of these regimes has greatly increased, but the ensuing picture of them has necessarily been slightly patchwork. Even though such disciplinary studies have produced an enormous amount of information on different aspects and practices of these entities, a more fundamental dynamic may still be lacking from this picture.

As there are crucial issues between, across and beyond different disciplines linked to the factors and processes which mediate the working of the whole, an interdisciplinary approach is needed to make more sense of these complex dynamics. An interdisciplinary approach to wholeness is adopted in this book to better make sense of the Nordic welfare states as states of civilisation. The Nordic welfare state could be conceived as a formative field affording combinations of possibilities and potentialities 
so that the selection between them can take place according to past history, present perception and future-oriented innovation.

The Nordic welfare state as a whole is, here, understood as a complex web of relations. These relations are bound together by practices of trust. In other words, trust is a formative process of the whole. Trust instantiates the quality of relations. We can distinguish four dimensions of trust: trust in oneself, trust in ourselves, trust in others and trust in their interaction. Trust in oneself is manifest in autonomy, trust in ourselves is manifest in participation, trust in others is manifest in inclusion and trust in their interaction is manifest in sustainability. Autonomy, participation, inclusion and sustainability comprise the four dimensions of the Nordic welfare state as a whole and endow the key perspectives of the research and also organise the structure of this book.

From these perspectives it is possible to recognise and analyse how the formative force of trust amplifies collective social creativity, without which the Nordic welfare states would not have become what they are now. The crucial characteristic of the Nordic welfare states is that trust is a formative process of the whole and ultimately signifies active trust in the human person and their social interaction, leading to social creativity, rather than just passive trust in the given system. This fact also explains why the Nordic welfare states do not leave human interaction to the mercy of market forces, and argues that the proper functioning of the markets can greatly profit from the formative force of trust embedded in human interaction.

Social creativity entails crossing traditional borders and presupposes the courage to face the wicked problems of the times. The existing institutions need to be constantly reorganised, as has happened in the Nordic welfare states. These states have actually followed advice similar to Machiavelli's, who emphasised that whoever wants to succeed in governing a country has to keep track of the changing circumstances and, hence, adjust the governing techniques accordingly. He also gave advice to rulers, especially in times of great upheaval and turmoil, to go back to the original founding principles and deliberate their significance in these new circumstances.

This is of vital importance in circumstances where a new utopia challenges the previous hegemonic register in dominance, so that there is a tendency - well described by Karl Mannheim (Mannheim, 1936 [1959]) - to turn it into an ideology, if it cannot renew itself in line with its original founding principles. The Nordic welfare states are now surrounded by a set of circumstances where the neoliberal utopia 
challenges the Nordic ethos of welfare and its original founding principles of equality, solidarity, public responsibility, universalism and autonomy.

Globalisation is here. Both apt and dubious claims have been made in the name of globalisation. Many of them are hardly more than contestable half-truths. One such claim is that the Nordic welfare states are being overrun by globalisation. Globalisation is both a challenge and an opportunity for the Nordic welfare states. Almost all internationally available indicators of citizens' welfare, economic sustainability, politicoadministrative performance and social cohesion exemplify the success of the Nordic countries in terms of human wellbeing, equality, low rates of poverty, life-satisfaction, stability, safety and security, trust, personal and press freedom, rule of law and reliability of elections and governance. We must, though, remember that these are average indicators and that the Nordic welfare states also have many significant differences.

For a great number of foreign observers the Nordic countries have appeared (even as far back as in F.D. Roosevelt's America) and still appear as a kind of paragon model or best practice to be learnt about or to be followed. Prominent international conferences have been regularly organised outside Scandinavia to study and discuss the past, present and future of the Nordic welfare states, often from a comparative (even critical) perspective. These discussions have been carried out all too often in terms of the 'Nordic model' portrayed as a paradigmatic and parametric design of its functioning. Even if such models include and convey highly relevant information about the performance and development of the Nordic welfare states, such a static, ultimately ahistorical, approach cannot capture the fundamental forces and motive powers of these societies in transformation.

To find answers explaining the 'Nordic success' and its present challenges, we must penetrate the deep structures of these societies, and the societal relations which keep the societies together and running. The goodness of these relations - social, economic, political, cultural, juridical - should make the cumulatively causal interoperability of these societies understandable. From a relational perspective, it is possible to understand how and why universalism, public responsibility, equality, solidarity and personal autonomy are relational rationalities of action.

The Nordic welfare states were never constructed according to some pre-given model, as if their contours would have been first outlined on some blueprint. These welfare regimes were not only built from the top-down, but also patiently and stepwise from the bottom-up. The notion of the Nordic welfare state has to be understood in an integral sense as comprising of multiple-stranded chains and networks of relations and 
cross-linkages between them. The piecemeal cumulative construction of the Nordic welfare states accentuates the mode and manner in which different domains, arenas and fields of practice and action are relationally mediated in these societies. The private and the public, the market and the state are relationally mediated and balanced, rather than existing as plain opposites. The role and rules of institutions is crucial in this in-between. Institutions should be understood as patterns of relations and not only as patterns of behaviour. Individual behaviour in this institutional context should be also relationally understood.

The starting point of this book is that the quality of its societal relations, to a great extent, explains the success of the Nordic countries. The close relations between the individual citizen and the state are of crucial significance in these countries. But these relations cannot be seen as an outcome or as a replication of some kind of counterfactual social contract. Societal relations mediate not only citizens and state concretely but also employers and employees, men and women, the well-to-do and the vulnerable, as well as trust and expectations. These relations offer channels for conflict resolution between different interests in society. The relational perspective reveals how and why a given society, rather than another, is able to find a path of balanced development.

In the light of the available indicators we can talk of strong Nordic democracy. The strength of this democracy is also relationally based. This helps to explain why it has been able to cope with severe social problems such as poverty and exclusion. The history of the Nordic democracy coincides with that of the welfare state and makes it perfectly clear that the social questions on the agenda need not have downplayed the political quest for freedom. On the contrary, it can strengthen this quest by deepening our understanding of freedom and democracy. Strong democracy needs free citizens, but their freedom must be contextually and relationally determined as personal autonomy.

Personal autonomy means that the freedom of a person is not burdened by all kinds of factual dependencies, many of which can be directly connected to difficulties and hardships condensed in the formula of social question. Lars Trägårdh was perfectly right in writing that for the Swedish welfare state

an overarching ambition has been to liberate the individual citizen from all forms of subordination and dependency in civil society, the poor from charity, the workers from their employers, wives from their husbands, children from their parents. In practice, the primacy of individual autonomy has been institutionalized through a plethora of laws and policies. (Berggren and Trägårdh, 2010) 
This conception of autonomy is the exact opposite to that of neoliberalism which equates personal autonomy with negative freedom.

John Dewey wrote in the 1920s that

what is not so generally acknowledged is that the understanding and generative conditions of concrete behavior are social as well as organic: much more social than organic as far as the manifestation of differential wants, purposes and methods of operation is concerned. To those who appreciate this fact, it is evident that the desires, aims and standards of satisfaction which the dogma of 'natural' economic processes and laws assume are themselves socially conditioned phenomena. They are reflections into the singular human being of customs and institutions; they are not natural [...] propensities. They mirror a state of civilisation. (Dewey, 2016)

This kind of pragmatically relational thinking which Dewey represents comes very close to the thinking of those Nordic intellectuals who, since the 1920s and even earlier, have personally inspired and contributed to the construction of the Nordic welfare state as a civilisational achievement. An effort is made in this book to analyse and evaluate the Nordic welfare states as such states of civilisation characterised by the high quality of their societal relations manifested in trust.

There are four relational aggregates which are decisive for the future of the Nordic welfare states. Each chapter in this book is located thematically in one of these topics. These relational topics address autonomy, participation, inclusion and sustainability. Autonomy refers to a human condition in which a person's experienced relations are such that he or she is able to master and manage his or her own life and decisions. It reflects trust in oneself. Participation refers to a mode of action which influences people in a common endeavour to change their circumstances. It reflects trust in ourselves. Inclusion refers to a state of circumstances in which all involved are so related that they belong together in such a fashion that they can contribute according to their own capabilities. This reflects trust in others. Sustainability refers to complex processes which relate people to each other and balance their relations with the environment helping them face (with precaution) uncertainty and contingency. It reflects trust in their interaction. The actual functioning and transformation of the Nordic welfare state is thus always environmentally embedded and conditioned.

Neoliberalism is a slippery notion which usually says too little about too much. If we want to disclose some of the means and modes which help manage our life, neoliberalism is, however, appropriate to use when carefully clarified. Neoliberalism is a bio-political mode of conducting our conduct. It has autonomy, participation and inclusion as objects to be 
worked on intellectually and governmentally. Neoliberalism seeks to untie those societal relations which it sees as inhibiting and stiffening the proper functioning of the market mechanism. Markets must be also constantly invigorated to function optimally as if markets should be helped to help themselves. Since this call can be only heard by people, neoliberalism aims at becoming a kind of self-fulfilling prophecy.

Neoliberalism argues that any human situation can be best managed when conceived economically. It is argued that when people organise their conduct according to a market-oriented rationality, they will optimally contribute to the common good simultaneously increasing their own chances in life. This reasoning naturally echoes Mandeville's fable. The major targets of neoliberalism have been influential policy makers and public servants in government and state offices, since the primary aim of neoliberalism has been to encourage and persuade states themselves to start acting as if they were private corporations, and accordingly, renew their internal and external relations. However, practices such as new public management (NPM), austerity, activation, restructuration, retrenchment and privatisation measures cannot simply be reduced to consequences of neoliberalism, even though during the past three decades neoliberalism has exerted an enormous influence, not only in the Anglo-Saxon countries, but also in the Nordic countries.

A critical question of neoliberalism concerns autonomy, which has been guaranteed and institutionalised in the Nordic countries through a plethora of laws and policies expressive of strong Nordic democracy. In this Nordic solution, a strong democracy and social security empower citizens and their aptness for action, who can thus promote this strong democracy through their own actions. In this way autonomy, participation and inclusion are closely related as cumulatively caused. This represents the ideal of democratic citizenship as social citizenship. However, it must be asked how viable this social citizenship is or will be in coping with the challenge of neoliberalism and similar rationalities to come which praise the virtues of market access, market citizenship and a competitive state in the age of globalisation and transnationalism.

Globalisation refers to free movement of money, capital and commodities, but also labour, people and ideas. In this way distances between people and their situations shrink, their events take place faster and faster and their interrelations become ever denser and more tightly linked. Globalisation signifies an all-pervasive transformation of the global space-time of human action. In the context of integral world capitalism the existing societal relations are being dissolved and reworked to the extent that the parable 'all that is solid melts into air' seems quite pertinent. What are ultimately at stake in this bio-political transformation 
are the life-worlds and life-styles of people and their localities, and even human worth as such (Foucault, 1990, pp. 138-43).

Globalisation does not mean the annihilation of borders but their de-territorialisation. It does not mean the end of man but his refashioning. The bio-political transformation has profound impacts on the conceptions and convictions about what it is to be human and what our rights and responsibilities are. These issues were already pivotal at the beginning of the Nordic welfare states. There had to be some basic common understanding and common human experience concerning what it means to be human and to live together. The ideas of universalism, solidarity, equality and public responsibility were crucial for the establishment of the Nordic welfare regime.

To exist and develop, the relational Nordic welfare state cannot give up its fundamental principles and premises which manifest in the Nordic ethos of welfare. However, the significance and content of these fundamental principles need to be reconsidered in these new circumstances of globalisation and trans-nationalisation where their execution is altogether more difficult nationally than before. This is not just a major social and political challenge for the Nordic welfare states, but it can also be a legal and a constitutional challenge. The important matter to remember is that constitutions are also relational, and this is a particularly significant reason why trans-nationalisation and globalisation can be such a considerable constitutional challenge to the Nordic welfare states. A notable expression of this quest is not just European integration by law, but also the role of individual and human rights in the discourse and practices of the Nordic welfare states, especially since the 1990s.

A crucial factor behind the success of the Nordic welfare states has been their great capacity to balance opposing interests, forces and contradictory tendencies. Balancing is a relational practice of mediation and conflict resolution, and, thus, calls for participation. As a process, balancing naturally takes time since it is ultimately a question of balancing different ways of life. Balancing is also a crucial factor in promoting autonomy and inclusion. If autonomy can be strengthened by balancing sociality and asociality - to put it in Kantian terms - then inclusion can be strengthened by balancing equality and difference. These kinds of balancing practices, to a varying degree, have been characteristics of the Nordic welfare states.

Balancing and mediating different interests can also promote sustainability in different societal dimensions. An outstanding example of such a balance has also taken place between competition and cooperation. This is the manner in which the Nordic welfare states have been able to boost a virtuous circle of development as a cumulative outcome of common 
efforts. The positive denominator of these efforts must be transversal interaction between different domains if sustainable societal development is effectively pursued. This means, above all, a balanced man-nature relationship. It means, in other words, the combining of preservation and novelty in such a fashion that can penetrate society's domains most creatively. Such a creative key to sustainability may be also found in the profitable market action of those innovative enterprises which have successfully adopted public responsibility for sustainability as their trademark.

Environmental sustainability is so closely linked with other forms of sustainability that it cannot succeed without them. They are all dependent on definite common human actions. The case in point is the social protection and empowerment of vulnerable people. In this case social sustainability can be only achieved by connecting personal autonomy, inclusion and participation and this does not succeed if these people are not given the chance to realise their own potentialities and capabilities. For this to happen the circumstances need to be such that their own action is not hampered by any strong top-down hierarchy or regulation. However, there are also more sophisticated and interlinked forms of regulation, which can also block their action in a counterproductive fashion to sustainability. Such a form of conducting the conduct of persons would force people to think and act against their interest.

Balancing finds its opposite in the practice of forcing. Forcing the truth so that other alternatives are dismissed as wrong (perverted, futile, jeopardised) is a typical procedure of neoliberalism. This is often the manner in which neoliberalism challenges the Nordic welfare states. Inclusion has been challenged by forcing the precarisation workfare policies, incentives and activation based on the idea of market access. If market access justice is applied as a means of forcing, then it can easily collide with the Nordic ethos of welfare. Hence, globalisation can be made to challenge the Nordic welfare states by accelerating the race to the bottom. This could also occur by way of immigration if it is not managed along the principles of equality of difference. Socio-economic problems with populist political effects can further arise if labour market precarisation gains strength. All this naturally depends on the adopted labour market, activation and inclusion policies which are, at present, contestable and heated issues on the political agenda in the Nordic countries. But these are certainly not the only critical issues of ongoing political struggles in which forcing plays a major role.

Environmental sustainability also offers an arena for forcing besides being the fatal question of our future. Climate is not only shaped by natural forces (climate forcing) but also by human forcing. Neoliberalism 
is an example of human forcing which tries to compel human life (styles) and activity into dominant trajectories of commodity and money circulation. If we add to that the fact that immigration has primarily been a consequence of war and poverty, and in the future most probably also of climate change, our challenges multiply. Even if the Nordic countries are in a better position than many other countries to cope with them, they may also find themselves to be on the brink of no return. In this situation we must make decisions and adopt conventions which totally renew our traditional ways of life.

The Nordic welfare state is a complex web of interconnected relations. This is how the chapters in this book have approached the Nordic welfare states and accordingly contextualised their particular research questions and objectives. This has been done by either examining how the Nordic welfare states have managed their affairs in new changing circumstances or by examining how the new changing circumstances have challenged the Nordic welfare states. The challenges facing the Nordic welfare state, therefore, play a crucial role in both of these approaches even if the manner of posing the questions and giving answers changes direction within them. The chapters in this book emphasise how the Nordic welfare state is particularly challenged by the neoliberal offensive and how it can be also the challenger of such utopian schemes. The outlines of the contents of each chapter already illustrate the multiple means and modes of such confrontations.

The first part of the book, Autonomy, begins with Sanford F. Schram's chapter about neoliberalism and poverty. The chapter scrutinises the relationship of the poor to those who are more fortunate and in a position to affect their life chances. Among those in relation to the poor are state actors who are assigned responsibility to monitor, manage, surveil and discipline welfare recipients to become market-compliant actors. These neoliberal relations to poverty are becoming more closely examined as the welfare state comes under pressure to integrate recipients into the market economy, while simultaneously reducing the state's burden for sustaining them. A comparative analysis between countries of these shifts in the relations between the poor and their state managers points to the variegated ways nations are enacting neoliberal welfare policy reforms.

In the next chapter, Sakari Hänninen penetrates the fundamental normative order of the Nordic welfare state. The overarching metaprinciple of this order is equality. The relational nature of equality is conceptualised in terms of interests, conventions and institutions. As a relation, equality is multi-dimensional so that we can speak of equality in terms of what, why, how and whom. Politics matters in the Nordic welfare states because the promotion of equality demands that opposite 
interests are mediated and unavoidable conflicts are balanced. This has been the strength of the Nordic political democracy and social citizenship. It is an outcome of such democratic politics which is able to creatively cope with new challenges. The largest challenge at present the Nordic welfare states are facing is to find out how to promote equality of difference at a time when the neoliberal offensive has forcefully landed in the Nordic countries.

Nina Witoszek ends the first part by asking whether there is a Nordic humanism. According to Witoszek, sustainable modernity is as much a creation of political and economic institutions and social movements as it is a summa summarum of cultural texts, norms, rituals and philosophical traditions. The main interest lies in the question: to what extent can the Scandinavian countries' successes as 'well-being societies' be attributed to the potency of a unique Nordic humanism? How has it evolved? Who have been its main drivers and how has it been replicated? In what way has it interacted with political and economic realms? And finally, what are the challenges to Nordic humanism today? This takes a semioticevolutionary perspective of the shared Nordic founding tradition, highlighting in particular the role of 'Ostromian' small groups and individuals in solidifying humanism in the Nordic education system and self-image.

In the second part of the book, Participation, social citizenship and participation is discussed. Paolo Borioni focuses on the relational quality of equality. This is seen as a clear outcome of collective political action. Borioni sees parity as a complex idea of the 'primacy of politics' bringing together various agents. The chapter focuses on the analysis of the significance of the parity between labour and capital and the parity between export-led competitiveness and wage-led domestic growth. It can be shown that these parities have helped to make it possible to construct a 'virtuous circle' between efficiency, solidarity, security and equality in the Nordic countries. In the present circumstances of ordoliberal influence, it is evident that equality is not a permanent quality but can be reversible. Ordo-liberalism distorts the Nordic socio-political system by regulating through hierarchy and inequality rather than parity and equality. This chapter examines more closely how far and deep such ordo-liberal regulation has penetrated Denmark and Sweden. Finally, it will be outlined what kind of pressures and challenges on the Nordic welfare states the change from parity to hierarchy, from equality to inequality, has already posed.

Pauli Kettunen challenges the conventional images of the Nordic model. Applying an approach which is sensitive to historical and political aspects of language and concepts, the chapter argues that a particular notion of social citizenship has developed in the Nordic countries in 
which interests rather than rights were put into the centre. Such a notion of social citizenship was associated with two intertwined ideas which were important in the development of the Nordic pattern of social reform: the idea of symmetry between workers and employers and the idea of a virtuous circle between divergent interests. With these concepts, democracy and citizenship have been combined with paid work and conflicting interests. This combination has been questioned by the projects for competitive national (and European) communities responding to globalised and financialised capitalism. The vigorous comparisons of 'models' and the popularity of the concept of 'the Nordic model' can be seen as an aspect of this current transformation.

In the third part, Inclusion, the focus is on the changes of inclusion or, to be more precise, the shift from interests to rights. Toomas Kotkas presents the idea that Nordic social security and social welfare systems were a result of a practical moral-political discourse based on the idea that everyone was to be included in society. From this perspective, society at large has been viewed as responsible for taking care of all its members. Since the 1990s, the human and individual rights discourse has gained strength throughout the Nordic countries. In some countries, such as in Finland and in Norway, new social or human rights provisions have been also amended in the constitution. Despite the increased attention to constitutional social and human rights, there is so far indecisive evidence of their practical significance concerning social security and/or social welfare policy. The chapter scrutinises how the strengthened rights discourse has appeared in the children's day care system in Finland and it discusses the nature of trust in the Nordic countries.

Kaarlo Tuori discusses the idea of a multi-dimensional European constitution, where the political and juridical constitutions are complemented by sectoral ones, such as an economic constitution, and poses the question of whether the sectoral constitutions include a social one. The answer is affirmative, but with some important qualifications. These qualifications have implications for the concept of justice, which inform the European social constitution: instead of solidaristic social justice, the European social constitution embodies access justice. The European social constitution does not replace national social constitutions (welfare states) but complements them. The main contributions of the European social constitution lie in fields that are on the fringes of the welfare state, legally speaking in what has been called regulative private law (e.g. consumer law). The European constitution also places constraints on national welfare states. These constraints, however, derive from the European economic constitution, rather than the social constitution. 
The title of the last part of the book is Sustainability. The concept brings contradictive views on the future. Monika Berg and Paula Saikkonen examine environmental sustainability in the Nordic welfare states. The future of the welfare system and citizens' wellbeing requires that humans do not cause irreversible damage to nature, yet risk-avoidance should be adjusted to other societal concerns and functions. The chapter discusses relational rationalities and focuses on knowledge production. Knowledge and information are used in many ways in decision-making processes and also to legitimise decisions already made. The sciencepolicy interface is seen as a relation or actually a relation of multiple relations. Even though the research brings more knowledge about complex environmental degradation, political decision making seems to progress on linear trajectories. As there is always a great deal of uncertainty in decisions made concerning sustainability, it is a question of coping with uncertainty. The social and ecological systems should be seen as relationally compatible in order to achieve a sustainable welfare system.

The chapter by Minna Kivipelto, Merita Jokela, Sanna Blomgren and Marek Perlinski discusses the challenges and functioning of Nordic welfare states from the perspective of social sustainability and asks how the lives and welfare of the most vulnerable people are managed by the state at different administrative levels and in cooperation with other agencies. The chapter examines professional social work in Finland by means of the domain theory. Although examples are derived from the Finnish social welfare agencies and analysed with a theory originally developed to understand Swedish social welfare services, the analysis is contextualised and the results are evaluated more generally in the Nordic setting. Despite their shared values and common traits, Sweden and Finland also display significant differences, for instance, regarding the professional status of social work, as well as differences in tasks and governance. The aim of this is to help understand social sustainability as the security and welfare of all citizens - and those living in the country from a relational perspective.

Peer Hull Kristensen, Eli Moen and Kari Lilja approach sustainability from a different angle. They begin by demonstrating how the Nordic welfare states, strong unions and various institutions providing patient capital have promoted forms of enterprises that have secured participatory forms of work-organisation and are oriented towards developing socially and environmentally responsible practices which are unknown to most countries. However, these regimes seem to have become weaker since the late 1980s. The authors ask whether this change means a digression from the most civilised form of capitalism. The chapter takes a 
relational approach. It shows how the relation between the state, labour market, distinct actors in the market and enterprises can create sustainable embeddedness of firms in the first place, and how this relational configuration can continue, even when an actor such as the state seems to withdraw from the configuration.

\section{REFERENCES}

Berggren, H. and L. Trägårdh (2010), 'Pippi Longstocking: The autonomous child and the moral logic of the Swedish welfare state', in H. Mattson and S.-O. Wallenstein (eds), Swedish Modernism: Architecture, Consumption and the Welfare State, London, UK: Black Dog Publishing Limited, pp. 10-23.

Cooke, G. and R. Muir (eds) (2012), The Relational State: How Recognising the Importance of Human Relationships Could Revolutionise the Role of the State, London: The Institute for Public Policy Research (IPPR).

Dewey, J. (2016), The Public and its Problems: An Essay in Political Inquiry, Athens, Ohio: Swallow Press.

Foucault, M. (1990), The History of Sexuality. 1, An Introduction. New York: Vintage Books.

Mannheim, K. (1936), Ideology and Utopia: An Introduction to the Sociology of Knowledge, reprinted 1959, New York: Harcourt, Brace \& World, Inc. 